\title{
Design and Implementation of a Portable Computer Based Induction Motor Supervisory System
}

\author{
Oshevire Patrick ${ }^{1}$, Oladimeji Tolulope ${ }^{2}$, Adedayo Ajibade ${ }^{3}$ \\ ${ }^{1}$ Department of Electrical-Electronic-Engineering, College of Technology, Federal University of Petroleum \\ Resources (FUPRE), Effurun, Nigeria \\ ${ }^{2}$ Department of Electrical-Electronic-Engineering, School of Engineering, The Federal Polytechnic, Ado-Ekiti, \\ Nigeria \\ ${ }^{3}$ Department of Electrical-Electronic-Engineering, College of Engineering, Afe Babalola University, Ado-Ekiti, \\ Nigeria \\ Email: ask4pat2001@yahoo.com, tolulopett@yahoo.com, aded1d1@aol.co.uk
}

Received 21 March 2014; revised 21 April 2014; accepted 28 April 2014

Copyright (C) 2014 by authors and Scientific Research Publishing Inc.

This work is licensed under the Creative Commons Attribution International License (CC BY). http://creativecommons.org/licenses/by/4.0/

(c) (i) Open Access

\begin{abstract}
The aim of this research paper is to monitor an induction motor (single or three-phase) while working or running using a portable computer. Parameters measured include supply voltage, stator coli temperature and casing temperature. For the temperatures of both stator and casing, temperature sensors were used. The sensor senses the temperature and sends its output to the analogue to the digital integrated circuit for further processing. The supply voltage is also monitored by a circuit and integrated circuit. The project on completion was tested and the parameters displayed on the portable computer. The objectives of the project are: The supply system can measure the following parameters: supply voltage, stator coil temperature, casing temperature. Display the data on the PC screen with the possibility of settings to establish range, limits and alarm indicators when these are exceeded. The program should be able to save data of the log entry with time on a dedicated file as record for future analysis.
\end{abstract}

\section{Keywords}

ADC-Analog to Digital Converter, Induction Motor, PC-Personal Computer, Stator

\section{Introduction}

The advent of the electric motor, whatever type it may be has helped the modern civilization a lot in power gen-

How to cite this paper: Patrick, O., Tolulope, O. and Ajibade, A. (2014) Design and Implementation of a Portable Computer Based Induction Motor Supervisory System. Smart Grid and Renewable Energy, 5, 121-127. 
eration, control and mechanization which has been the major force that is moving civilization forward. The importance of the electric motor cannot be overemphasized as it is major equipment in virtually all industries where manufacturing of products takes place.

Regular maintenance of these motors is imperative because of their importance as a breakdown would result in lost time and revenue. This is also important as their expected life span predicted by the manufacturers under stipulated working conditions can be achieved. Just like the proverbial saying that "there is no smoke without fire", before an induction motor will break down completely, there are signs and observations that would appear which must never be allowed to occur and if they do, they must be controlled immediately. Among the several things that have been observed to reduce the lifespan of motors, high temperatures other than the safe range within and outside the motor have been a major cause of reduction in life span of the electric motors. This is so as every other condition that can adversely affect the motor would eventually result in temperature increment above limits and it can also result in burnt stator coils.

In the industrial cycles, where the motor is part of the machines involved in the production cycle control, it is very important that such motors must be operated within limits as operation outside limits could be very costly to the company. The controls of these motor operating parameters also demand that one must measure them in order to enhance control and the parameters that can be measured are: supply voltage, temperature of stator coil and temperature of the casing.

Normally, these parameters can be measured by personnel in the establishment manually by physical inspection which may be tedious but a system can be designed such as that these measurement can be carried out automatically without a personnel's physical presence, hence this paper was born out of the need for an instrumentation system whereby these parameters of the induction motor can be measured and displayed on a control panel. This offers several benefits including being able to monitor the operation of the motor, take a log of operating characteristics with time and alarm indications for extreme conditions outside the nominal range.

\section{Block Diagram of the Induction Motor Supervisory Circuit}

The design involves circuits that would measure certain parameters of the induction motor using appropriate sensors and the sensors output would be converted to digital signals after due processing and conditioning of the signals. This interface circuit would also be configured to make it compatible with the PC hardware.

The block diagram of the proposed supervisory system is shown in the Figure 1.

\section{Design of the PC Controlled Induction Motor Supervisory Circuit}

\subsection{Design Specifications}

The design analysis of the PC controlled induction motor supervisory circuit is presented with the specifications the system intends to achieve: [1] [2].

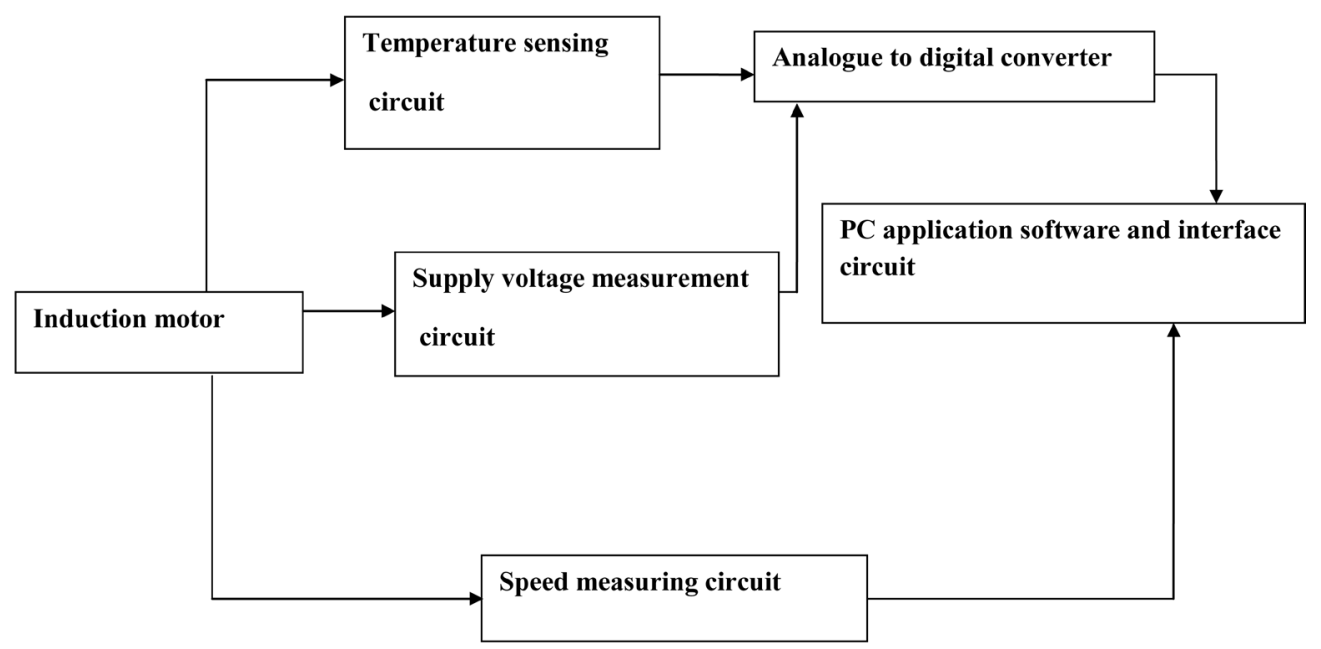

Figure 1. Showing the block diagram of induction motor supervisory circuit. 
- Supply voltage measurement $=0-250 \mathrm{~V}$ ac

- Supply voltage $=220 \mathrm{~V}$

- Frequency $=50 \mathrm{~Hz}$

- Stator temperature range $=10^{\circ} \mathrm{C}-60^{\circ} \mathrm{C}$

- Casing temperature range $=10^{\circ} \mathrm{C}-60^{\circ} \mathrm{C}$

The design of the circuit would be treated under the following sub-heads which are functional blocks of the system.

- Power supply

- Temperature sensor circuit

- Analog to digital converter (ADC)

\subsubsection{Power Supply}

The circuit needs a power supply of $+5 \mathrm{~V}$ for the digital I to power the circuit. For this reason a $12 \mathrm{~V}$ step down transformer was used to power the circuit [3] [4].

Output secondary voltage $=12 V_{\text {rms }}$

Peak Voltage $V_{p}=12 \times \sqrt{2}=16.9 \mathrm{~V}$

Peak output voltage from bridge rectifier

$$
V_{P R}=V_{p}-2 V_{d}=16.9-2(0.7)=16.9-1.4=15.5 \mathrm{~V}
$$

An I.C bridge Rectifier RBPC6010A used in the design and has the following specifications:

KBPC6010A Bridge Rectifier

Output Current=6 A@50ㄷ

I surge $(\max )=125 \mathrm{~A}$

Reverse voltage $V_{R R M}=100 \mathrm{~V}$

Ripper Voltage $=\frac{I_{O}}{2 F C}$

where $I_{O}=$ Regular Output Current

$V_{r}=$ Ripple Voltage

For $I_{O}=200 \mathrm{~mA}, V_{r}=1 \mathrm{~V}$

$$
\begin{gathered}
C_{1}=C_{2}=\frac{2 \times 10^{-3}}{2 \times 50 \times 1} \\
C_{1}=C_{2} 0.002 \mathrm{~F}=2000 \mu \mathrm{F}
\end{gathered}
$$

This is a capacitor with at least $2000 \mu \mathrm{F}$ and working voltage of $16.9 \mathrm{~V}$ is needed. The one chosen for the design is $250 \mathrm{~V} 2200 \mu \mathrm{F}$. In order to get the needed regulated voltage, I.C voltage regulator was used in the power supply [3], the power supply unit is shown in Figure 2.

Regulator data: 7805

Maximum Input Voltage $=300 \mathrm{~V}$

Maximum Output Voltage $=5.5 \mathrm{~V}$

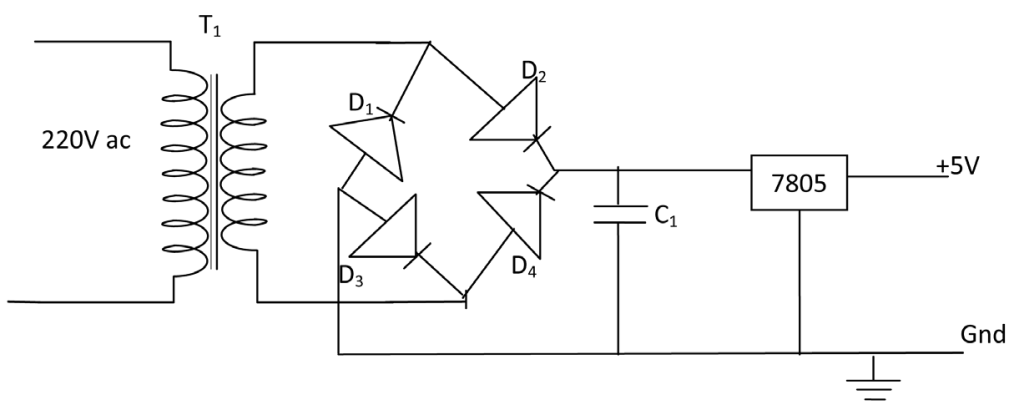

Figure 2. Showing the power supply unit. 
Drop out Voltage $=2 \mathrm{~V}$

Operating temperature $=V 0^{\circ} \mathrm{C}-150^{\circ} \mathrm{C}$

\subsubsection{Design of the Temperature Sensing Stage}

The temperature sensor chosen for the design is the popular LM35 IC temperature sensor giving a linear voltage output of $10 \mathrm{mV}$ per degree Celsius. Available in two versions, one operating from $0^{\circ} \mathrm{C}-100^{\circ} \mathrm{C}$ (DZ version) the other is from $-40^{\circ} \mathrm{C}-+100^{\circ} \mathrm{C}$ (CZ version).

These devices are housed in TO-92 plastic packages and provide a low cost solution to temperature measurement [2] [5] [6].

Ideally suited for ambient temperature measurement such as providing cold junction compensation for thermocouples, the technical specifications are shown as:

Temperature range

LM35DZ $-40^{\circ} \mathrm{C}$ to $110^{\circ} \mathrm{C}$

Absolute Voltage (max) $+35 \mathrm{~V}$ to $-0.2 \mathrm{~V}$

Operating Voltage range $+30 \mathrm{~V}$ to $+0.4 \mathrm{~V}$

Quiescent current@5 V 91 A typical

Accuracy@25ㄷ

$\mathrm{LM} 35 \mathrm{CZ} \pm 0.4^{\circ} \mathrm{C}$

$\mathrm{LM} 35 \mathrm{DZ} \pm 0.9^{\circ} \mathrm{C}$

The circuit will use two units of LM35 temperature sensor, one to sense the temperature of the stator coils during operation and the other to sense the temperature of the casing. The output of the sensors would be connected to the ADCs through electronic switches that would be used for selecting or multiplexing both sensors. The temperature sensor and switch selector is shown in Figure 3.

\subsubsection{Design of the Analog to Digital Converter (ADC)}

The analogue to digital converter (ADC) function is to convert Analog voltages received from the temperature sensors and from the supply voltage stages to digital information that is sent to the PC.

The type of ADC of choice is one that can output the information in binary format. The ADC0804 fits this type of ADC choice. The Analogue to digital converter stage was designed using a dedicated ADC chip ADC0804.

The ADC0801, ADC0802, ADC0803, ADC0804 and ADC0805 are CMOS 8-bit successive approximation $\mathrm{A} / \mathrm{D}$ converters that use a differential potentiometer ladder-similar to the 256R products. These converters are designed to allow operation with the NSC800 and INS8080A derivative control bus with TRI-STATE output latches directly driving the data bus. These A/Ds appear like memory locations or I/O ports to the microprocessor and no interfacing logic is needed.

Differential Analog voltage inputs allow increasing the common-mode rejection and offsetting the Analog zero input voltage value. In addition, the voltage reference input can be adjusted to allow encoding any smaller Analog voltage span to the full 8 bits of resolution [7]-[10].

The frequency of the internal oscillator, $F_{\text {osc }}=\frac{1}{R C}$

Choosing $F_{\text {osc }}=310 \mathrm{kHz}$

And $C=180 \mathrm{pF}$, thus

$$
\begin{gathered}
R=\frac{1}{310,000 \times 180 \times 10^{-12}} \\
R=17921 \Omega
\end{gathered}
$$

A value of $18 \mathrm{k} \Omega$ was chosen as the closest value in the market.

\subsubsection{Operational Principle of the PC-Based Induction Motor Supervisory System}

The complete circuit diagram is presented in the Figure 4. The power supply stage consists of the transformer T1, bridge rectifier D1 - D4, filter capacitor C1, and 7805 voltage regulator. The transformer steps down the mains voltage of $220 \mathrm{~V}$ to $12 \mathrm{~V}$ ac. The bridge rectifier rectifies the ac to dc. Capacitors C1 is a filter capacitor 


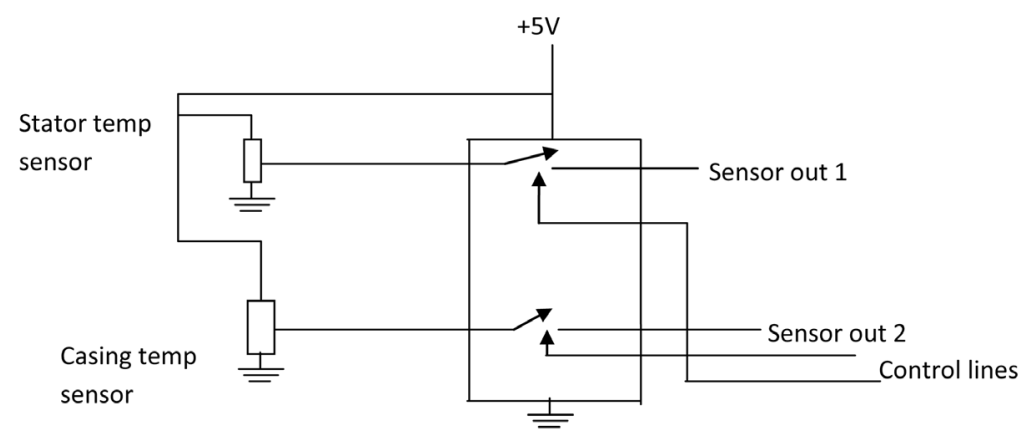

Figure 3. Showing temperature sensor and switch selector.
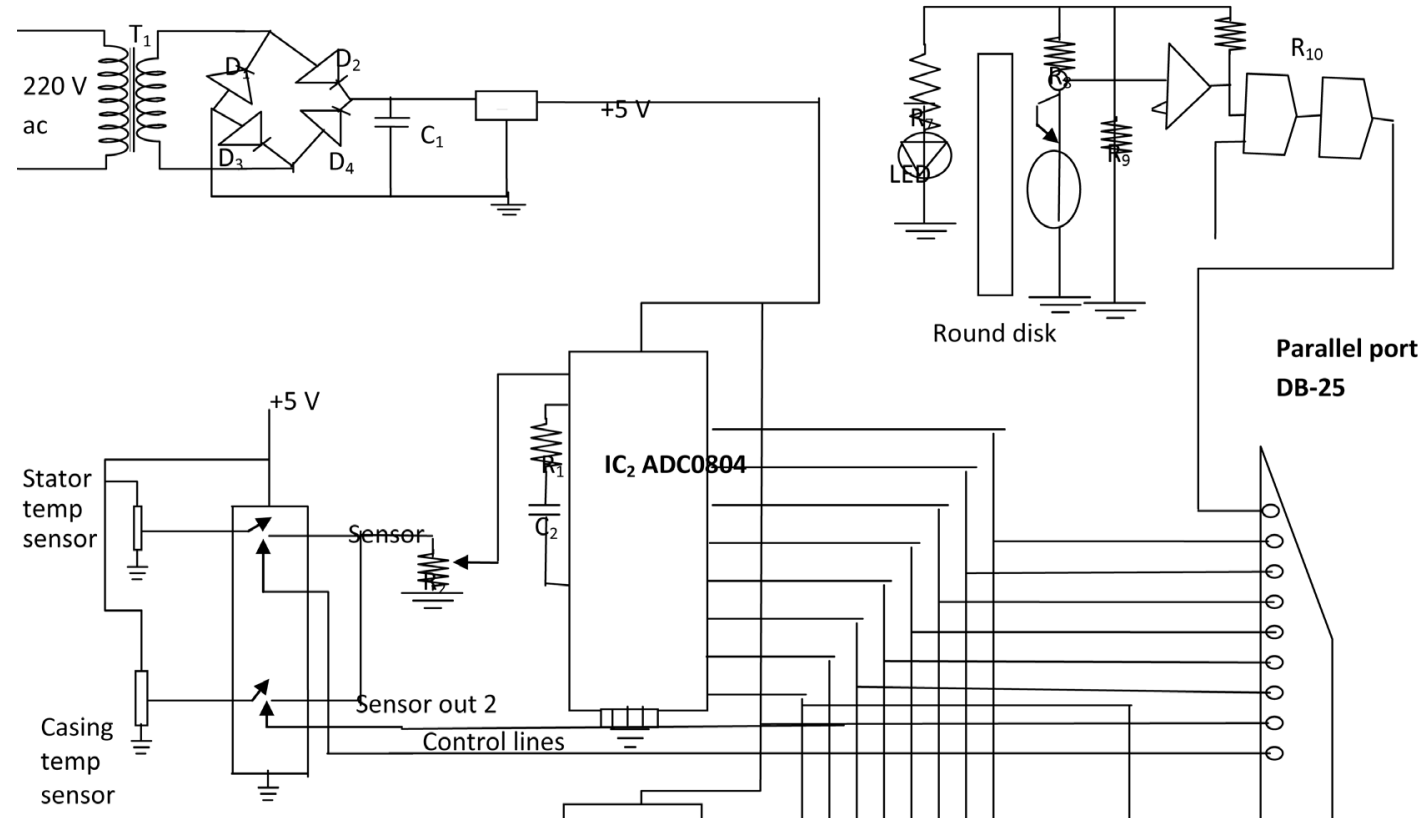

DB-25

Temperature sensor and switch selector
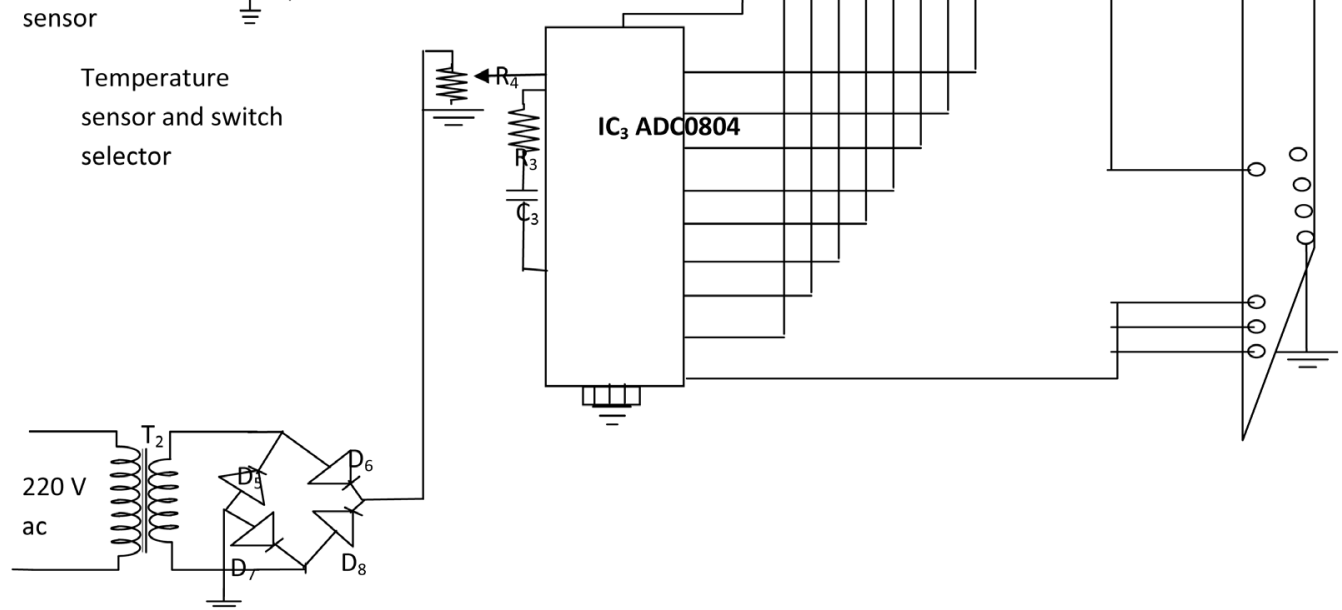

Figure 4. Complete circuit diagram of portable computer based induction motor supervisory system.

to filter off ac ripples in the dc voltage. 7805 is a positive $5 \mathrm{~V}$ voltage regulator meant to supply a constant $5 \mathrm{~V}$ to the circuit.

The temperature measuring circuit consists of two temperature sensors Lm35DZ, which gives an analogue voltage output per degree change in temperature. These voltages are then converted to digital data by the ADC0804 (IC2) Analog to digital converter via a 4066 integrated circuit switch (IC1), which is a complementary 
metallic semi-conductor electronic switch.

The supply voltage to the induction motor is monitored through the step-down transformer T2 and bridge rectifier D5 - D8. The transformer steps down the voltage to $12 \mathrm{~V}$ which is rectified to dc and fed to ADC chip IC3. IC3 converts it to digital then sends to parallel port (DB-25).

The measuring speed of the induction motor is monitored through the power supply mains, a round disc is placed at the rotor of the induction motor with a hole bored on it, and the light emitting diode senses the speed of the rotor. The NAND gate in the speed circuit shapes the signal to pulses and sends to the parallel port DB-25.

\section{Construction}

The construction work started immediately after the completion of the design calculations and determination of the component values. The components were initially set up on a bread-board to test the circuit before being transferred to the vero board.

The breadboard stage started with the connection of both temperature sensors, followed by the two Analog to digital converter (ADC) circuits. The ADC data output were then connected to the PC parallel port cable DB-25.

The supply voltage for the induction motor circuitry was the next stage to set up and after completion, continuity test was done to ensure proper connection.

The power supply stage was finally connected after making sure all other stages and their components were rightly connected. Each stage had its components mounted according to the circuit design specifications. The layouts of the components were carefully done so that the circuit can work as planned. Each of the stages and their components were then connected to the others using jumping wires. All stages were set up according to design. Power was supplied to the circuit and the appropriate tests carried out.

This test was done after the visual basic code development and carefully debugging. After the circuit has been tested and adjustments made, the components were then transferred to the vero board for permanent soldering. The soldering on this board is done similar to that done on the breadboard. The soldering work started with the power supply stage since it was needed for testing the other stages of the design. The power stage was followed by the temperature sensor stage, Analog to digital (ADC) were connected too to the PC parallel port. With the aid of a voltmeter, these stages were confirmed to be in good working condition. Care must be taken when soldering to ensure proper soldering joints and bonds and portions of the copper strip-lines that needed isolation were properly isolated.

After complete construction work the circuit was tested. The complete circuit was placed in a white PVC plastic casing.

\subsection{Testing}

The testing was done stage by stage as each stage construction was completed. This approach is best as it enables one to quickly identify stages that are not working properly and to be corrected. The power supply stage was done first of all to ensure that the $+5 \mathrm{~V}$ was supplied. The test showed they were okay.

The output of the temperature sensor was measured using a voltmeter and the logic state of the ADC was checked also to confirm that the output is changing to change in temperature as heat was applied to the sensor.

\section{Test Results}

The results of the test mainly presented in Tables 1-3 are the temperature test for the stator core and casing of the induction motor for testing.

Table 1. Results of the stator temperature test with $60^{\circ} \mathrm{C}$ trip temperature using digital thermometer.

\begin{tabular}{ccc} 
S/No & Measured temperature & PC temperature display $\left({ }^{\circ} \mathrm{C}\right)$ \\
\hline 1. & 28 & 28 \\
2. & 27 & 27 \\
3. & 29 & 29 \\
4. & 30 & 30 \\
5. & 26 & 26 \\
\hline
\end{tabular}


Table 2. Results of the casing temperature test with $60^{\circ} \mathrm{C}$ trip temperature using digital thermometer.

\begin{tabular}{ccc}
\hline S/No & Measured temperature $\left({ }^{\circ} \mathrm{C}\right)$ & PC temperature display $\left({ }^{\circ} \mathrm{C}\right)$ \\
\hline 1. & 27 & 28 \\
2. & 28 & 27 \\
3. & 29 & 30 \\
4. & 30 & 30 \\
5. & 32 & 31 \\
\hline
\end{tabular}

Table 3. Results of the Induction motor supply voltage test with digital voltmeter.

\begin{tabular}{ccc}
\hline S/No & Standard Voltage $(\mathrm{V})$ & PC voltage readings $(\mathrm{V})$ \\
\hline 1. & 200 & 205 \\
2. & 205 & 209 \\
3. & 210 & 213 \\
4. & 215 & 216 \\
5. & 219 & 219 \\
\hline
\end{tabular}

\section{Recommendations}

The following recommendation has been made based on the knowledge that one has acquired from the design and implementation in the course of this research work.

- Use of complete sensor unit that can be connected straight to the PC without the parallel port but through USB port as this will lead to faster operation and smaller circuitry as most devices can power themselves from the USB port.

- Writing of efficient codes to collect this data and link them up (export them) to dedicated software's like MATLAB for analysis.

- Design a circuit that can measure the speed of the motor using microprocessor device.

\section{References}

[1] Hughes, E. (1995) Electrical Technology. 7th Edition, ELBS with Longman, 378-382, 392-400, 523-532.

[2] Theraja, B.L. and Theraja, A.K. (1999) A Textbook of Electrical Technology in SI Units. 22nd Edition, S. Chand, New Delhi, 53, 57 and 63.

[3] Whitehead, R.J. (1988) Mastering Electronics. 3rd Edition, McGraw Hill, New York.

[4] Kanfman, M. and Seidmen, A.H. (1988) Handbook of Electronics Calculations for Engineers and Technicians. McGraw-Hill Book Company, New York.

[5] Horowtiz, P. and Hill, W. (1989) The Art of Electronics. 2nd Edition, Cambridge University Press, USA.

[6] Wolf, S. and Smith, R.F.M. (2003) Student Reference Manual for Electronics Instrumentation Laboratories. 2nd Edition, Prentice Hall, Upper Saddle River, USA

[7] Direct Industry Web Page from the Internet: Sensors. Google Search.

[8] Internet Search. www.allaboutciruit.com

[9] 3 October 2010. http://www.circuitstoday.com

[10] Tooley, M. (2006) Electronics Circuits, Fundamentals \& Applications. 3rd Edition, Jordan-Hill Inc., Oxford. 